\title{
EL VALOR NORMATIVO DE LA CONSTITUCIÓN ESPAÑOLA
}

\author{
EDUARDO GARCÍA DE ENTERRÍA \\ Catedrático de Derecho Administrativo
}




\title{
EL VALOR NORMATIVO DE LA CONSTITUCIÓN ESPAÑOLA
}

POR

\author{
EDUARDO GARCÍA DE ENTERRÍA
}

Catedrático de Derecho Administrativo (*)

La Constitución de 1978 ha marcado decisivamente nuestra historia política, como todas las Constituciones anteriores (aunque quizás también en este extremo con mayor profundidad que ninguna, se exceptuamos la de Cádiz, que produjo la ruptura con el Antiguo Régimen), pero también nuestra historia jurídica, lo cual resulta ya completamente novedoso respecto de todas sus precedentes.

Sólo también la Constitución de Cádiz había marcado hasta ahora entre todas las Constituciones una época nueva en la evolución de nuestra historia del Derecho, en virtud de la recepción que opera de los grandes principios del "monumento jurídico de la Revolución francesa" (soberanía nacional frente a poder regio absoluto, división de poderes, independencia, legalización y desestamentalización del poder judicial, legalización y libre acceso a la función pública, contra su estamentalización y patrimonialización, supresión de señoríos, primacía de la propiedad individual, con desvinculación, desamortización, "cerra-

$\left(^{*}\right)$ Este trabajo se publica simultáneamente en la obra colectiva dirigida por M. Aragon y J. Martínez Simancas, La Constitución y la práctica del Derecho, 3 volúmenes, Aranzadi, 1998. 
miento" de fincas y liberación o redención de cargas, censos y servidumbres personales, gobierno por leyes generales y no por privilegios o fueros paccionados, "reino de la Ley", codificación, levantamiento de aduanas interiores y creación de un mercado nacional, administración racionalizada, etc.). El cortejo de consecuencias de las ideas que aportaron lo constituyentes de Cádiz y que sólo parcialmente, pero efectivamente, acertaron a imponer en el mundo jurídico, a través de las esporádicas y problemáticas puestas en vigor del texto constitucional, no habia tenido precedentes. Fue una verdadera revolución jurídica fundacional y de fondo, una de las más profundas de nuestra historia, revolución sobre cuyos principios, en definitiva, se organizó todo el Derecho y el Estado que entonces se intentó establecer, que concluyó asentándose y que subsiste en lo esencial hasta hoy mismo.

La revolución jurídica que aporta la Constitución de 1978 ha sido de muy distinto signo. Por una parte, ha acertado a concluir la guerra civil larvada que se mantuvo durante siglo y medio con varias explosiones sangrientas, y que había mantenido tardígradamente la vieja oposición en el seno social e institucional (papel de la Iglesia, opuesta a la libertad religiosa, la libertad de expresión y de asociación y para la que "el liberalismo es pecado") entre Antiguo Régimen y democracia.

Esta oposición histórica había perdurado en Francia, como ha estudiado Furet, desde la Revolución hasta ya entrada la III República. Pero esa pugna básica se mantuvo viva política y socialmente (si no jurídicamente) tres cuartos de siglo más (entierro de Víctor Hugo, "boulangisme", "affaire" Dreyfus, guerra de las congregaciones y separación de la Iglesia del Estado, "Action Française", fascismos de los años treinta, Vichy). Sólo la derrota militar de los fascismos en la II Guerra Mundial liberó a la vieja derecha francesa (política, intelectual, religiosa) de la fascinación que había continuado ejerciendo en ella la imagen idealizada de un orden natural, orgánicamente integrado, con tensiones menores paternalmente resolubles, ordenada alrededor de valores personales, locales y religiosos, es decir, llanamente, la imagen de un Antiguo Régimen estéticamente y desiderativamente retocada. Esta corriente de opinión, nada desdeñable en su fuerza, era, pues, efectivamente "reaccionaria", pretendía un retorno, más o menos confesado, a la situación anterior a 1789. Sólo el asombroso error que esa derecha cometió, sacrificando su nacionalismo tradicional al odio a la República, aliándose con el ocupante alemán en el "colaboracionismo" (error apenas explicable en personajes como Maurras), sólo este error acabo con ella definitivamente. La alternativa democracia-Antiguo Régimen dejo de existir entonces definitivamente. La llamada derecha de- 
jó de tener a partir de 1945 cualquier connotación verdaderamente reaccionaria en el sentido dicho.

Más claro es el caso de Alemania, de Italia y de Centroeuropa. El "principio monárquico", como un poder autónomo del monarca en pie de igualdad, de hecho de superioridad, con el principio democrático, subsistió hasta el final bélico de los Imperios centrales en 1918. El democratismo puro de la Constitución de Weimar malvivió en medio de golpismos de todo signo y de los "poderes excepcionales" o dictatoriales del Presidente en virtud del art. 48, hasta que, finalmente, fue definitivamente arrumbado en 1933 por el nazismo. En Italia el más temprano fascismo precedió diez años a esa misma caída. Todos los Estados salidos de Versalles sufrieron crisis análogas a esa misma caída. También sólo en la postguerra de 1945 y, en el caso de los Estados caídos bajo la órbita soviética en 1989 (trabajosamente, hasta ahora mismo), ha podido decirse que el principio democrático haya quedado instaurado en esa importante parte de Europa.

Nuestra propia historia constitucional no ha diferido, pues, demasiado en sus grandes líneas de la europea, contra lo que suele decirse, y sólo la larga persistencia del franquismo, edificado sobre el temor - cuidadosamente cultivado- a reabrir una atroz guerra civil, que sí fue singular en Europa, nos asignó un retraso visible en la recuperación de la soberanía democrática incondicionada.

La Constitución de 1978 es la primera, con excepciones apenas semánticas (Constituciones de 1869 y de la I y la II Repúblicas), que ha acertado a implantar el principio democrático como único principio político legitimador. Lo verdaderamente notable es que esto haya sido hecho por un consenso entre todas las fuerzas políticas, herederas, por unas y otras vias, tanto de las que protagonizaron el enfrentamiento bélico civil de 1936-1939, como las de la mínima institucionalmente, pero efectiva en su extensión real, "tercera España" (fórmula de Salvador de Madariaga), que fue la que se negó a alinearse con ninguno de los bandos en lucha. La gran hazaña histórica de la Constitución está en el logro sin precedentes, que ha puesto término a más de siglo y medio de luchas políticas existenciales y ha creado, sin más, por ello mismo, un espacio político común, por vez primera general y nacional. Esto ha hecho que la Constitución de 1978 se presente como algo que no tenía precedentes en nuestra historia, como la decisión efectivamente constituyente del pueblo entero, como una expresión auténtica de un verdadero pacto social fundacional con la intención de instituir un marco duradero de estructuración perdurable del sistema democrático como sistema efectivo. 
Pero a esta básica significación jurídico-política, la Constitución de 1978 unió una novedad radical que la ha singularizado en toda nuestra historia constitucional, la de haberse deliberadamente configurado para ser una norma jurídica perfectamente operativa por sí misma en su función de cabeza y fundamento de todo el ordenamiento jurídico.

Los enunciados contenidos en las Constituciones, bajo la vestidura formal de un lenguaje juridico, no habían sido nunca consideradas como normas jurídicas propiamente dichas, salvo en cuanto establecían los campos de actuación de los poderes superiores. Pero aun esta eficacia normativa reducida no contó nunca (la limitada y poco feliz actuación del Tribunal de Garantías Constitucionales de la II República permite ser casi categórico) con la posibilidad de una garantía judicial de cualquier carácter. De hecho se trataba, por tanto, de pautas de actuación que los poderes superiores deberían imponer según su respectiva fuerza relativa, intentando movilizar en su caso la opinión pública en favor de sus respectivas tesis, pero sin ninguna posibilidad de obtener un respaldo judicial formal.

Las elecciones podían ventilar así distintas interpretaciones constitucionales, de modo que la derrota de una de ellas podría significar la salida del sistema constitucional de las fuerzas derrotadas y su postulación abierta de un cambio constitucional expreso.

Si ese era el régimen de la "parte orgánica" de las Constituciones, la "parte dogmática" o de declaraciones de derechos y de principios, cuando existía (no la incluía el Estatuto Real de 1834, las de 1837 y 1845 redujeron al mínimo su contenido) carecía por sí misma de cualquier eficacia jurídica propia. Esas declaraciones y principios no podían ser invocados ante los Tribunales como normas de decisión de un proceso, fuera éste de cualquier clase. Desde que se instauró el recurso de casación en las jurisdicciones civil y penal y desde los orígenes de la jurisdicción contencioso-administrativa, el Tribunal Supremo declaró, sin una sola excepción, que la violación de cualquiera de esas normas constitucionales por las Sentencias recurridas no podía fundamentar ningún recurso de casación o contencioso-administrativo, que tales declaraciones y principios eran puramente "programáticas", dirigidas al legislador y no a los jueces, y que sólo en la medida en que el legislador aceptara desarrollar ese programa, y en la extensión que él soberanamente decidiese, los principios constitucionales llegarían a ser propiamente normas jurídicas aplicables por los Tribunales. 
La Constitución republicana de 1931, que es la primera que recoge la técnica de control jurisdiccional de la constitucionalidad de las leyes, atribuyo también al Tribunal encargado de esta función, el Tribunal de Garantías Constitucionales, el "recurso de amparo de garantías individuales cuando hubiera sido ineficaz la reclamación ante otras autoridades". Pero ni aun sobre esta base, cuya aplicación resultó escasamente efectiva, por lo demás, el Tribunal Supremo rectificó su doctrina sobre la naturaleza programática de los preceptos incluidos en la Constitución, atañente sólo al legislador pero sin eficacia propia para vincular a los jueces ordinarios como normas de decisión en sus sentencias.

Obvio es decir que el mismo criterio se aplicó durante la vigencia de las "Leyes Fundamentales" del franquismo, por todas las Salas del Tribunal Supremo.

La corrección radical de esta doctrina no tendría lugar sino por la Constitución de 1978. Ha sido en el orden jurídico estricto su gran aportación a la historia de nuestro constitucionalismo.

El texto constitucional comienza con la proclamación de los "valores superiores del ordenamiento juridico" (art. 1.1), de los cuales la libertad se descompone en todos los derechos fundamentales enunciados en su título I, derechos que son "fundamento del orden político y de la paz social" (art. 10.1), lo que los incluye directamente en dicho ordenamiento jurídico general, sin necesidad de ninguna conversión legislativa previa. Así lo afirma, por lo demás, el art. 53.1 de la propia Constitución, al precisar que "los derechos y libertades reconocidos en el capítulo II del presente título vincularán a todos los poderes públicos", no siendo discutible que los jueces y Tribunales son un poder público ("integrantes del poder judicial", precisa el art. 117.1). Pero aun un precepto mas general, el del art. 9.1, despeja toda duda y extiende el valor normativo directo de la Constitución a la totalidad de su contenido, en estos términos: "Los ciudadanos y los poderes públicos están sujetos a la Constitución y al resto del ordenamiento jurídico". Este precepto resulta especialmente claro: la vinculación (normativa, puesto que es una parte del "ordenamiento jurídi$c o ")$ de la Constitución no afecta sólo a los poderes públicos, entre los cuales están, sin duda posible, como ya hemos visto, los jueces y Tribunales; afectan también (efecto directo) a los ciudadanos mismos, que ganan, pierden, modulan sus derechos (e intereses legítimos) que, a su vez tienen derecho a la tutela judicial efectiva, en los términos del art. 24.1. De este modo, la vieja y más que secular doctrina del carácter meramente programático de la Constitución y la correlativa 
negación de su valor como norma de decisión de los procesos ha quedado definitivamente liquidada.

Así ha venido a consagrarlo en el plano técnico el art. 5.1 de la Ley Orgánica del Poder Judicial: "La Constitución es la norma suprema del ordenamiento jurídico y vincula a todos los Jueces y Tribunales". $\mathrm{El}$ art. 7.1 especifica este principio general a los derechos fundamentales: "Los derechos y libertades reconocidos en el capitulo II del Título I de la Constitución vinculan, en su integridad, a todos los jueces y Tribunales y están garantizados bajo la tutela efectiva de los mismos".EI parágrafo 2 del propio art. 7 concreta aún más para los derechos fundamentales susceptibles de recurso de amparo: "En especial, los derechos enunciados en el art. 53.2 de la Constitución se reconocerán, en su caso, de conformidad con su contenido constitucionalmente declarado, sin que las resoluciones judiciales puedan restringir, menoscabar o inaplicar dicho contenido". Difícilmente se podría ser más claro.

En fin, el carácter normativo directo de toda la Constitución incluye a sus "principios" aparentemente más abstractos, como ha precisado la jurisprudencia constitucional (Sentencias 15/1982, 254/1993, 31/1994, etc.).

La eficacia normativa de la Constitución se hace presente en su propio texto al disponer su disposición derogatoria tercera que quedan derogadas "cuantas disposiciones se opongan a lo establecido en esta Constitución". La vieja concepción de que la Constitución era una mera invitación al legislador para que dictase las verdaderas normas jurídicas queda así totalmente desvirtuada: sin necesidad de ningún complemento, la Constitución interfiere y deroga por ella misma todas las normas existentes contrarias a sus preceptos y principios.

\section{III}

Pero la Constitución no sólo es una norma jurídica plena, como acabamos de ver, sino que resulta que es la norma jurídica suprema y que, como tal, puede exigir a las propias Leyes parlamentarias razón de su validez. Los arts. 161.1.a), 162.1.a), 163 y 164 de la propia Constitución regulan, en efecto, un control de constitucionalidad de las leyes de las que puede resultar la invalidez general de éstas (art. 163.1). Este control corresponde en exclusiva al Tribunal Constitucional, según el modelo estructural kelseniano, seguido en general en los países euro- 
peos. Este sistema singular plantea la cuestión, en la que algún constitucionalista se ha perdido, de si sólo ese peculiar órgano especializado que es el Tribunal Constitucional sería el competente para aplicar e interpretar la Constitución. La exclusividad en el ejercicio de la jurisdicción constitucional implicará la exclusividad en la aplicación e interpretación de la norma constitucional. Este aserto, que podría encontrar algún apoyo en la doctrina kelseniana estricta de donde el sistema procede, sería gravemente erróneo por lo que respecta a la Constitución española.

El Tribunal Constitucional tiene, en efecto, un monopolio, que es el de rechazo o expulsión de las leyes (y productos normativos equiparados) del ordenamiento mediante su declaración de inconstitucionalidad; esta función no está al alcance de ningún otro juez o Tribunal. Pero si leemos con alguna atención el art. 163 de la Constitución, que es el que articula la relación entre Tribunal Constitucional y Tribunales ordinarios, resulta claro que a estos últimos corresponde un importante papel en la interpretación y aplicación de la Constitución. El art. 163 dice: "Cuando un órgano judicial considere, en algún proceso, que una norma con rango de Ley aplicable al caso, de cuya validez dependa faIlo, pueda ser contraria a la Constitución, planteará la cuestión ante el Tribunal Constitucional...". No puede, por tanto, el órgano judicial declarar por sí mismo una ley contraria a la Constitución, que es lo que corresponde al Tribunal Constitucional en exclusiva, pero sí es suya la competencia de "considerar" que esa contradicción puede producirse y de resolver esa duda por la negativa, esto es, en favor de la constitucionalidad abstractamente planteable.

Pero esa simple consecuencia implica por sí sola una larga serie de facultades aplicativas de la Constitución que ésta defiere a los jueces y Tribunales ordinarios:

1. Les corresponde la facultad de enjuiciamiento previo de constitucionalidad de las Leyes, enjuiciamiento que ha de preceder a cualquier aplicación de éstas.

2. Suya es también la facultad de resolver ese enjuiciamiento previo en sentido positivo, esto es, del juicio positivo de constitucionalidad de la Ley, que condiciona propiamente la aplicación de ésta como norma de decisión del proceso.

3. Les pertenece también el juicio de "posibilidad" de inconstitucionalidad de la ley ("considere (...) que (...) puede ser contraria a la Constitución", dice el art. 163), supuesto en el 
cual tendrán la obligación de plantear cuestión prejudicial de inconstitucionalidad al Tribunal Constitucional. Convendrá notar que esa "posibilidad" ha de referirse a una contradicción formal entre la Ley y la Constitución y no a una simple duda subjetiva; el Tribunal Constitucional insiste en su jurisprudencia en que la cuestión de inconstitucionalidad no está para resolver dudas interpretativas de los jueces, sino para resolver contradicciones formales entre la Constitución y las Leyes que los jueces positivamente aprecien.

4. Pero quedan fuera de esa obligación de remitir la cuestión al Tribunal Constitucional la eventual inconstitucionalidad de Reglamentos, que los jueces y Tribunales ordinarios deben decidir por sí mismos inaplicando el Reglamento en contradicción con la Constitución (art. 6 de la Ley Orgánica del Poder Judicial).

5. La misma solución respecto de actos jurídicos, privados o públicos (y aquí, especialmente, por la jurisdicción contencioso-administrativa), cuya inconstitucionalidad arrastrará su ineficacia. Especialmente relevante en este caso será la tutela de los derechos fundamentales que la Constitución proclama en su Título I, capítulo segundo. A este respecto, convendrá retener el texto del art. 7 de la Ley Orgánica del Poder Judicial de 1985: "Los derechos y libertades reconocidos en el Capítulo segundo del Título l de la Constitución vinculan, en su integridad, a todos los jueces y tribunales $y$ están garantizados bajo la tutela efectiva de los mismos. En especial, los derechos enunciados en el art. 53.2 de la Constitución se reconocerán, en todo caso, de conformidad con su contenido constitucionalmente declarado, sin que las resoluciones judiciales puedan restringir, menoscabar o inaplicar dicho contenido". Obsérvese que en este caso de protección de derechos fundamentales esta Ley pretende claramente hacer de la Constitución más energéticamente norma propia de decisión judicial, a cuyo contenido debe subordinarse (extremando, si pudiera decirse, la obligación de "interpretación de las Leyes de conformidad con la Constitución" a que inmediatamente nos referimos) cualquier otro enunciado legal o administrativo referente a dichos derechos fundamentales. Por otra parte, el art. 62.1.a) de la Ley de Procedimiento Administrativo Común de 1992 declara la nulidad de pleno derecho de los actos administrativos que lesionen los derechos fundamentales. 
6. Finalmente, los jueces y Tribunales, para todas las operaciones enunciadas en los apartados anteriores, estarán obligados a interpretar conforme a la Constitución todas las normas del ordenamiento, cuestión a la que nos referimos mas despacio seguidamente.

Este cuadro sistemático, nada banal en cuanto al contenido que refleja, está sustancialmente recogido en los artículos 5 y 6 de la LOPJ de 1985:

“Art. 5.1. La Constitución es la norma suprema del ordenamiento jurídico, y vincula a todos los Jueces y Tribunales, quienes interpretarán y aplicarán las Leyes y los Reglamentos según los preceptos y principios constitucionales, conforme a la interpretación de los mismos que resulta de las resoluciones dictadas por el Tribunal Constitucional en todo tipo de procesos.

2. Cuando un órgano judicial considere, en algún proceso, que una norma con rango de ley, aplicable al caso, de cuya validez dependa el fallo, pueda ser contraria a la Constitución, planteará la cuestión ante el Tribunal Constitucional, con arreglo a lo que establece su Ley Orgánica.

3. Procederá el planteamiento de la cuestión de inconstitucionalidad cuando por vía interpretativa no sea posible la acomodación de la norma al ordenamiento constitucional".

“Art. 6. Los Jueces y Tribunales no aplicarán los Reglamentos o cualquier otra disposición contrarios a la Constitución, a la Ley o al principio de jerarquía normativa".

Quizás convenga resaltar que la vinculación de los Tribunales ordinarios a la doctrina jurisprudencial del Tribunal Constitucional, que hemos visto que declara de manera formal el artículo 5.1 LOPJ, se entiende como una manifestación de la vinculación a la Constitución, en cuanto que esa doctrina jurisprudencial expresa una interpretación cualificada de la Constitución misma realizada por el "intérprete supremo" de ésta, como califica al Tribunal Constitucional su Ley Orgánica, artículo 1. En su labor propia de interpretación y aplicación de la Constitución, los jueces y Tribunales ordinarios no pueden apartarse de la interpretación que a la Constitución ha dado su "intérprete supremo". Esta interpretación resultará no sólo de las Sentencias que resuelvan recursos o cuestiones de inconstitucionalidad contra las Leyes, sino, como precisa el precepto, "de las resoluciones dictadas por el Tribunal Constitucional en todo tipo de procesos", incluyendo, pues, los 
recursos de amparo y los conflictos de atribución y, por supuesto, de las sentencias tanto estimatorias como desestimatorias.

Ese valor cualificado de la doctrina del Tribunal Constitucional da a la misma un valor virtualmente normativo.

7. A este régimen general convendrá añadir una competencia transitoria de jueces y Tribunales, la de declarar la derogación o "inconstitucionalidad sobrevenida"de las leyes en vigor en el momento de la entrada en vigor de la Constitución, por efecto de la disposición derogatoria $3 .^{a}$ de ésta, que declaró "derogadas cuantas disposiciones se opongan a lo establecido en esta Constitución". El Tribunal Constitucional, a la vista de las soluciones que para el mismo supuesto habían decidido los Tribunales Constitucionales alemán (declarar la derogación correspondo en exclusiva a los Tribunales ordinarios) e italiano (no pueden declararla los Tribunales ordinarios, sino que éstos han de elevar cuestión de inconstitucionalidad al Tribunal Constitucional), han construido una tesis original: la derogación pueden declararla por sí mismos los Tribunales ordinarios, pero cabe también que eleven cuestión de inconstitucionalidad al Tribunal Constitucional (Sentencias constitucionales de 2 de febrero, 8 de abril de 1981 y 3 de julio de 1997). El efecto de la constatación derogatoria será el mismo, pero en el segundo caso la sentencia constitucional le dará efectos erga omines (art. 164.1: las sentencias "que declaren la inconstitucionalidad de una Ley o de una norma con rango de Ley (...) tienen plenos efectos frente a todos"). Resulta, por ello, aconsejable la segunda vía en los supuestos más complejos o dudosos, para hacer efectivo el principio (constitucional: art. 9.3) de seguridad jurídica.

\section{IV}

Lo más relevante de ese cuadro de actuación judicial de la Constitución es el principio de interpretación conforme a la Constitución de todo el ordenamiento, que ha recogido, como acabamos de notar, el artículo 5.1 de la LOPJ. 
Este principio es un derivado del principio de supremacía y se formuló por ello originalmente en los Estados Unidos (obligación de interpretar las Leyes in harmony with the Constitution) y en Alemania (Verfassungskonforme Auslegung der Gesetze). El Tribunal Constitucional formuló el principio desde su primera sentencia de inconstitucionalidad (Sentencia de 2 de febrero de 1981), lo repite de manera constante y sistemática y de su doctrina lo tomó la LOPJ para que los jueces la tengan constantemente presente en su actividad enjuiciadora.

Proviene el principio, como se comprende fácilmente, de la necesidad judicial de buscar interpretaciones de las leyes que salven su concordancia con la Constitución a fin de limitar en lo posible la declaración de inconstitucionalidad de aquéllas. Acierta a expresarlo el párrafo 3 del artículo 5 de la LOPJ: "Procederá el planteamiento [por los jueces] de la cuestión de inconstitucionalidad cuando por la vía interpretativa no sea posible la acomodación de la norma al ordenamiento constitucional".

Por su parte, el propio Tribunal Constitucional, por un principio elemental de economía, que busca salvar en lo posible la subsistencia de las leyes y limitar al mínimo posible las declaraciones de inconstitucionalidad, que producen siempre un grave trauma en el ordenamiento, incluso en ocasiones, como ha llegado a decir algún Tribunal Constitucional, una situación material de inconstitucionalidad no menos grave que la que se ha tratado de eliminar, utiliza con frecuencia las sentencias interpretativas de rechazo, en la que se salva la inconstitucionalidad de una Ley sobre la base de una determinada interpretación constitucional de la misma, interpretación que el Tribunal suele llevar al fallo. (La técnica es conocida también por el Conseil Constitutionnel francés en el nombre de conformité sous réserve).

De esas exigencias prácticas de la justicia constitucional se derivará a un principio general más amplio, el de la Constitución como clave de bóveda del ordenamiento, como expresión del "sistema de valores" (expresión que aparece con toda frecuencia en nuestra jurisprudencia constitucional) que articula las bases de la comunidad política y social de la nación, y que por ello contiene los grandes principios que ha de informar todo el ordenamiento. Ello explica la pretensión de la Constitución como informadora general del sistema jurídico, algo más, pues, que el de su consideración como un límite de no contradicción. 
La Constitución se erige asi en "contexto" necesario de todas las Leyes, para utilizar el tecnicismo que aparece en el artículo 3 de nuestro Código Civil cuando precisa que "las normas se interpretarán según el sentido de sus palabras, en relación con su contexto...". En otros términos, la exigencia de una interpretación sistemática de las normas, que obliga a oponer a éstas en relación con todas las demás del ordenamiento que puedan referirse, directa o indirectamente, a la materia de que se trate, implica que esa relación ha de establecerse siempre y necesariamente con la Constitución, a todos los efectos que quedaron enunciados en nuestra enumeración precedente.

En esa relación sistemática Constitución-norma concreta, la primera es precisamente la norma "dominante", esto es, la que prevalece en el conjunto para dar sentido específico al complejo normativo aplicable.

Este principio de interpretación conforme a la Constitución de todas las leyes justifica de manera especial que no sólo los preceptos de la misma formulados en términos formales normativos, sino también todos sus principios y "valores" resulten vinculantes para los jueces y para toda la tarea interpretativa realizada por la Administración o por cualquier agente jurídico operante en el seno del ordenamiento. Determina así, en buena parte, la práctica de una verdadera “jurisprudencia de valores", que es la que se está imponiendo en nuestra práctica judicial. 